\title{
ERRATUM
}

\section{Hydrogen technologies for energy storage: A perspective - ERRATUM}

In this article ${ }^{1}$, the units were incorrectly rendered; the correct units are given below.

- Liquid hydrogen is currently the most mature and conventional commercial method for storing and transporting bulk quantities of hydrogen, with a density of $71 \mathrm{~kg} / \mathrm{m}^{3}$

- HySTRA aims to supply liquid hydrogen produced in Australia that is transported via ship to Japan. The initial prototype transport ship is designed with a $1250 \mathrm{~m}^{3}$ tank volume

- The other conventional hydrogen storage method is as a compressed gas. The density of hydrogen gas is

\section{Marika Wieliczko}

Ned Stetson

DOI: https://doi.org/10.1557/mre.2020.43

significantly lower than liquid hydrogen, ranging from 11.5 to $50.5 \mathrm{~kg} / \mathrm{m}^{3}$

- As an illustrative example, the hydrogen density of water at ambient temperature and pressure is about $111.8 \mathrm{~kg} / \mathrm{m}^{3}$, whereas hydrogen is $40 \mathrm{~kg} / \mathrm{m}^{3}$ as a 700 bar compressed gas and $71 \mathrm{~kg} / \mathrm{m}^{3}$ as a liquid at $-253{ }^{\circ} \mathrm{C}$.

\section{REFERENCE:}

1. Wieliczko M. and Stetson N.: Hydrogen technologies for energy storage: A perspective. MRS Energy \& Sustainability, 7. Cambridge University Press. (2020). 